\title{
Prevalence and predictors of vitamin D deficiency in young African children
}

Reagan M. Mogire ${ }^{1,2^{*}}$ (D, Alireza Morovat ${ }^{3}$, John Muthii Muriuki ${ }^{1}$, Alexander J. Mentzer ${ }^{4,5}$, Emily L. Webb ${ }^{6}$, Wandia Kimita ${ }^{1}$, Francis M. Ndungu' ${ }^{1}$, Alex W. Macharia ${ }^{1}$, Clare L. Cutland ${ }^{7}$, Sodiomon B. Sirima ${ }^{8}$, Amidou Diarra ${ }^{8}$, Alfred B. Tiono ${ }^{8}$, Swaib A. Lule ${ }^{6,9}$, Shabir A. Madhi ${ }^{10}$, Manjinder S. Sandhu ${ }^{11}$, Andrew M. Prentice ${ }^{12}$, Philip Bejon ${ }^{1,13}$, John M. Pettifor ${ }^{14}$, Alison M. Elliott ${ }^{9,15}$, Adebowale Adeyemo ${ }^{16}$, Thomas N. Williams ${ }^{1,13,17}$ and

Sarah H. Atkinson ${ }^{1,13,18^{*}}$

\begin{abstract}
Background: Children living in sub-Saharan Africa have a high burden of rickets and infectious diseases, conditions that are linked to vitamin D deficiency. However, data on the vitamin D status of young African children and its environmental and genetic predictors are limited. We aimed to examine the prevalence and predictors of vitamin $D$ deficiency in young African children.

Methods: We measured 25-hydroxyvitamin D (25(OH)D) and typed the single nucleotide polymorphisms, rs4588 and rs7041, in the GC gene encoding the vitamin D binding protein (DBP) in 4509 children aged 0-8years living in Kenya, Uganda, Burkina Faso, The Gambia and South Africa. We evaluated associations between vitamin D status and country, age, sex, season, anthropometric indices, inflammation, malaria and DBP haplotypes in regression analyses.
\end{abstract}

Results: Median age was 23.9 months (interquartile range [IQR] 12.3, 35.9). Prevalence of vitamin D deficiency using $25(\mathrm{OH}) \mathrm{D}$ cut-offs of $<30 \mathrm{nmol} / \mathrm{L}$ and $<50 \mathrm{nmol} / \mathrm{L}$ was $0.6 \%(95 \% \mathrm{Cl} 0.4,0.9)$ and $7.8 \%(95 \% \mathrm{Cl} 7.0,8.5)$, respectively. Overall median 25(OH)D level was $77.6 \mathrm{nmol} / \mathrm{L}$ (IQR 63.6, 94.2). 25(OH)D levels were lower in South Africa, in older children, during winter or the long rains, and in those with afebrile malaria, and higher in children with inflammation. 25(OH)D levels did not vary by stunting, wasting or underweight in adjusted regression models. The distribution of Gc variants was Gc1f 83.3\%, Gc1s 8.5\% and Gc2 8.2\% overall and varied by country. Individuals carrying the Gc2 variant had lower median $25(\mathrm{OH}) \mathrm{D}$ levels $(72.4 \mathrm{nmol} / \mathrm{L}(\mathrm{IQR} 59.4,86.5)$ than those carrying the Gc1f $(77.3 \mathrm{nmol} / \mathrm{L}(\mathrm{IQR} 63.5,92.8))$ or Gc1s $(78.9 \mathrm{nmol} / \mathrm{L}(\mathrm{IQR} 63.8,95.5))$ variants.

Conclusions: Approximately $0.6 \%$ and $7.8 \%$ of young African children were vitamin $D$ deficient as defined by $25(\mathrm{OH}) \mathrm{D}$ levels $<30 \mathrm{nmol} / \mathrm{L}$ and $<50 \mathrm{nmol} / \mathrm{L}$, respectively. Latitude, age, season, and prevalence of inflammation and malaria should be considered in strategies to assess and manage vitamin D deficiency in young children living in Africa.

Keywords: 25-hydroxyvitamin D, Vitamin D deficiency, Africa, Children, Nutrition, Vitamin D binding protein, GC genotype

\footnotetext{
* Correspondence: reaganmoseti@gmail.com; satkinson@kemri-wellcome.org

'Kenya Medical Research Institute (KEMRI) Centre for Geographic Medicine

Coast, KEMRI-Wellcome Trust Research Programme, Kilifi, Kenya

Full list of author information is available at the end of the article
}

(c) The Author(s). 2021 Open Access This article is licensed under a Creative Commons Attribution 4.0 International License, which permits use, sharing, adaptation, distribution and reproduction in any medium or format, as long as you give appropriate credit to the original author(s) and the source, provide a link to the Creative Commons licence, and indicate if changes were made. The images or other third party material in this article are included in the article's Creative Commons licence, unless indicated otherwise in a credit line to the material. If material is not included in the article's Creative Commons licence and your intended use is not permitted by statutory regulation or exceeds the permitted use, you will need to obtain permission directly from the copyright holder. To view a copy of this licence, visit http://creativecommons.org/licenses/by/4.0/. The Creative Commons Public Domain Dedication waiver (http://creativecommons.org/publicdomain/zero/1.0/) applies to the data made available in this article, unless otherwise stated in a credit line to the data. 


\section{Background}

Vitamin D deficiency is estimated to be common worldwide [1], including in Africa [2]. Vitamin D deficiency is an important public health problem due to its link with a growing number of diseases [1]. Children may be at a higher risk of low 25-hydroxyvitamin D (25(OH)D) levels and related diseases [3] including rickets, infectious diseases and impaired growth and development $[1,3]$. Young children living in Africa have a high burden of nutritional rickets [4], infectious diseases, and account for more than half of all under-5-year mortality worldwide [5].

Few studies have investigated the prevalence of vitamin $\mathrm{D}$ deficiency in young African children and most have followed a case-control design to determine associations with specific disease conditions [2, 4, 6, 7]. Populationbased studies include a study from Nigeria with 218 preschool children aged between 6 and 35 months [8] and two studies from Tanzania, one with 581 infants aged 6 months [9] and another with 948 HIV-exposed (uninfected) infants [10]. Similarly, little is also known about the risk factors for vitamin D deficiency in African children. A single study found that $25(\mathrm{OH}) \mathrm{D}$ levels increased with age in 21 infants of Malawian mothers living with HIV [6], and seasonal variation in vitamin D status has been reported in school children in Algeria $(n=435)$ and South Africa $(n=385)$ [11, 12]. Vitamin D deficiency was associated with severe wasting in 21 young Kenyan children with rickets [4], but was not associated with sex, stunting, underweight or wasting in 581 Tanzanian infants [9]. Studies have reported conflicting findings regarding associations between vitamin D status and inflammation $[13,14]$; however, only a single study has been conducted in African children [7]. Similarly, only a few studies have evaluated the relationship between vitamin $\mathrm{D}$ status and malaria, with mixed findings $[9,10,15]$.

Genetic polymorphisms in the group-specific component gene, $G C$, in the $4^{\text {th }}$ chromosome that codes for Gc globulin (Gc), also known as the vitamin D binding protein (DBP), have been associated with vitamin D status and many pathophysiological conditions [16]. More than $85 \%$ of circulating vitamin D metabolites (including $25(\mathrm{OH}) \mathrm{D})$ are bound to DBP [16]. The combination of two GC SNPs (rs7041 and rs4588) give rise to three major DBP variants with different amino acid and glycosylation characteristics, Gc1f, Gc1s and Gc2, and six DBP haplotypes: Gc1f/1f, Gc1f/1s, Gc1f/2, Gc1s/1s, Gc1s/2 and Gc2/2 [16]. The DBP variants have been reported to differ in binding affinity and concentrations [16-18]. The Gc1f allele is most frequent in individuals of African ancestry, while Gc1s is more common in Europeans [17]. Nevertheless, little is known about the genetics of vitamin D and how it is related to vitamin D status in populations living in Africa. To our knowledge, only two small genetic studies in The Gambia $(n=237$ and $n=18$ ) have assessed the association between $25(\mathrm{OH}) \mathrm{D}$ levels and DBP haplotypes in Africa $[19,20]$.

Information on the prevalence and predictors of low vitamin D status in young African children is important in guiding public health policy, however, this information is limited in African populations. In the current study, we measured 25-hydroxyvitamin D (25(OH)D) levels in 4509 children living in Kenya, Uganda, Burkina Faso, The Gambia and South Africa and evaluated the prevalence and predictors of vitamin D deficiency.

\section{Methods \\ Study cohorts}

This study included young children living in Kenya ( $n=$ $1361)$, Uganda $(n=1301)$, Burkina Faso $(n=329)$, The Gambia $(n=629)$ and South Africa $(n=889)$. Details of these cohorts have previously been described [21-25] and are briefly summarised below.

\section{Kilifi, Kenya $\left(3.5^{\circ} \mathrm{S}, 39.9^{\circ} \mathrm{E}\right)$}

This is an ongoing community-based cohort aimed at evaluating immunity to malaria in children [21]. Children were followed up from birth to eight years with weekly follow-ups and annual cross-sectional surveys during which anthropometric measurements and blood samples were collected. Levels of $25(\mathrm{OH}) \mathrm{D}, \mathrm{CRP}$ and malaria parasitemia were measured in plasma samples from a single cross-sectional survey, based on the availability of samples archived at $-80^{\circ} \mathrm{C}$.

\section{Entebbe, Uganda $\left(0.1^{\circ} \mathrm{N}, 32.5^{\circ} \mathrm{E}\right)$}

The Entebbe Mother and Baby Study (EMaBS) is a prospective birth cohort study that was originally designed as a randomised controlled trial (ISRCTN32849447) aimed at evaluating the effects of helminths and anthelmintic treatment during pregnancy and early childhood on immunological responses to routine vaccinations and incidence of infections in childhood [22]. Anthropometry and blood samples were collected at birth, and at subsequent annual visits. Laboratory assays were conducted in samples from a single annual visit based on the availability of stored samples archived at $-80^{\circ} \mathrm{C}$.

\section{Banfora, Burkina Faso $\left(10.6^{\circ} \mathrm{N}, 4.8^{\circ} \mathrm{W}\right)$}

The VAC050 ME-TRAP Malaria Vaccine trial tested the effectiveness, safety and immunogenicity of a malaria vaccine in children between the ages of six and 17 months [23]. Anthropometry and blood samples were collected at multiple time-points after receipt of the experimental vaccine. Levels of $25(\mathrm{OH}) \mathrm{D}, \mathrm{CRP}$ and malaria parasitaemia were measured on stored plasma samples archived at $-80^{\circ} \mathrm{C}$. 


\section{West Kiang, The Gambia $\left(13.3^{\circ} \mathrm{N}, 16.0^{\circ} \mathrm{W}\right)$}

This study included children aged between two and six years recruited from 10 rural villages in the West Kiang region of The Gambia as previously described [25]. Anthropometry and biomarkers were measured in samples from a single cross-sectional survey at the start of the malaria season.

\section{Soweto, South Africa $\left(26.2^{\circ} \mathrm{S}, 27.9^{\circ} \mathrm{E}\right)$}

The Soweto Vaccine Response Study included infants of African heritage recruited from vaccine trials [24]. This study used stored plasma samples collected from infants that had received all of their routine Expanded Program on Immunization vaccines. The study was conducted in a non-malaria-endemic region and anthropometry and haemoglobin levels were not measured in this cohort.

\section{Laboratory assays}

Assays of 25(OH)D (chemiluminescent microparticle immunoassay, Abbot Architect) and C-reactive protein (CRP) (MULTIGENT CRP Vario assay, Abbot Architect) and $\alpha 1$-antichymotrypsin (ACT) (immunoturbidimetry, Cobas Mira Plus Bioanalyser, Roche) were performed. A verification of the $25(\mathrm{OH}) \mathrm{D}$ assay and the comparison of its results with those from an LC/MS method have been published previously [26]. In-house assessments of the assay showed heparinized plasma to give results that were on average $5.1 \%$ lower than those obtained on matching serum. The assay's performance was monitored by $12-$ hourly quality control checks, with overall CVs that ranged from $2.8 \%$ to $7.9 \%$ for mean $25(\mathrm{OH}) \mathrm{D}$ concentrations ranging from 21 to $116 \mathrm{nmol} / \mathrm{L}$ (Additional file 9: Figure S1). Over a 6-month period that spanned the 20week period of analyses, three sets of external quality assurance (DEQAS) data showed the method to have a mean (SD) bias of $-2.7 \%$ (7.6) against the all-laboratory trended values, and one of $-0.4 \%$ (7.7) against the target values. Malaria parasitaemia was detected using Giemsastained thick and thin blood smears.

\section{Definitions}

Vitamin D status was defined using 25(OH)D cut-offs of $<$ $30 \mathrm{nmol} / \mathrm{L},<50 \mathrm{nmol} / \mathrm{L}$, and $50-75 \mathrm{nmol} / \mathrm{L}$, as adapted from the Endocrine Society and the US Institute of Medicine guidelines [27-29]. Inflammation was defined as CRP level > $5 \mathrm{mg} / \mathrm{L}$ or $\mathrm{ACT}>0.6 \mathrm{~g} / \mathrm{L}$ [30]. Malaria parasitaemia was defined as the presence of asexual malaria parasites at any density. Height-for-age $z$-scores (HAZ), weight-for-age $z$ scores (WAZ), and weight-for-height z-scores (WHZ) were computed using the $2006 \mathrm{WHO}$ child growth standards [31]. Stunting was defined as $\mathrm{HAZ}<-2$, underweight as WAZ $<$ -2 and wasting as $\mathrm{WHZ}<-2$. Season was defined using 3 monthly intervals (1st season, December, January, February; 2nd, March, April, May; 3rd, June, July, August; 4th,
September, October, November). In South Africa, the seasons correspond to summer, autumn, winter and spring; in Uganda and Kenya, there are two rainy and two dry seasons; and in Burkina Faso and The Gambia, there is a single rainy and a single dry season, although the timing of the rains is often unpredictable and may vary $[12,32,33]$.

\section{Genotyping and SNP quality control}

Genomic DNA from study participants were genotyped using genome-wide SNP arrays (see Additional file 1: Supplementary Methods for more details). Two GC SNPs (rs7041 and rs4588) were retrieved from imputed data and their combinations used to classify participants into Gc variants; Gc1f (T and C), Gc1s (G and C) and Gc2 (T and A) and six DBP haplotypes; Gc1f/f (TT, CC), Gc1f/s (TG, CC), Gc1f/2 (TT, CA), Gc1s/s (GG, CC), Gc1s/2 (TG, CA), and Gc2/2 (TT, AA).

\section{Statistical analyses}

All statistical analyses were conducted using Stata Statistical Software: Release 15 (College Station, TX: StataCorp LLC) and R version 3.5.1 (https://www.R-project. org/). 25(OH)D levels were natural log $(\ln )$-transformed to normalise their distributions in regression analyses. Medians and geometric means for 25(OH)D levels were used to summarise average $25(\mathrm{OH}) \mathrm{D}$ levels for different groups. Between-group differences in median $25(\mathrm{OH}) \mathrm{D}$ levels were tested using Wilcoxon rank-sum test (two categories) and Kruskal-Wallis equality-of-populations rank test (more than two categories). Linear and logistic regression analyses were performed to evaluate the association between vitamin $\mathrm{D}$ status $(\ln -25(\mathrm{OH}) \mathrm{D}$ levels and $25(\mathrm{OH}) \mathrm{D}$ levels of $<50$ and between 50 and 75 $\mathrm{nmol} / \mathrm{L}$ compared to $>75 \mathrm{nmol} / \mathrm{L}$ ) and country, age, sex, season, stunting, underweight, wasting, inflammation, malaria, and DBP haplotypes and variants. Since few children had 25(OH)D levels $<30 \mathrm{nmol} / \mathrm{L}$, further analyses did not include this group. Multivariable regression analyses were adjusted for age, sex, season, inflammation, and study site, as appropriate.

We further searched PubMed and Embase for published studies that measured serum 25(OH)D levels in healthy children aged 0-8 years in Africa without date of publication or language restrictions. The search strategy is presented in Additional file 2: Table S1. We then carried out meta-analyses of low vitamin $\mathrm{D}$ status categories $(25(\mathrm{OH}) \mathrm{D}$ levels $<50$ and $<75 \mathrm{nmol} / \mathrm{L})$ and mean $25(\mathrm{OH}) \mathrm{D}$ levels using random effects models ('meta' $\mathrm{R}$ package).

\section{Role of the funding source}

The funders had no role in the study design, data collection, data analysis, data interpretation, or writing of the report. The corresponding authors had full access to all 
the data and had final responsibility for the decision to submit for publication.

\section{Results}

\section{Characteristics of study participants}

A total of 4509 infants and children with an age range of 0.2 months to 8 years and a median age of 23.9 months (interquartile range 12.3, 35.9) were included in the study (Table 1). Approximately half (49.1\%) of children were female. Overall prevalence of stunting, underweight and wasting was $25.4 \%, 15.6 \%$ and $6.4 \%$, respectively, and varied by country with the highest prevalence observed in Kenyan children. Overall prevalence of inflammation and asymptomatic malaria was $22.8 \%$ and $13.5 \%$, respectively, and varied by country with the highest prevalence observed in Burkina Faso $(33.9 \%$ and $21.1 \%$, respectively) (Table 1 ).

\section{Vitamin D status}

Overall median 25(OH)D level was $77.6 \mathrm{nmol} / \mathrm{L}$ (IQR 63.6, 94.2), and geometric mean 25(OH)D level was 77.0 $\mathrm{nmol} / \mathrm{L}$ (95\% CI 76.3, 77.7). Prevalence of vitamin D deficiency defined by $25(\mathrm{OH}) \mathrm{D}$ levels of $<50 \mathrm{nmol} / \mathrm{L}$ or $<$ $30 \mathrm{nmol} / \mathrm{L}$ were $7.8 \%(350 / 4509)$ and $0.6 \%(28 / 4509)$, respectively (Table 1$)$. A total of 1674 children (37.1\%) had 25(OH)D levels between 50 and $75 \mathrm{nmol} / \mathrm{L}$. The

Table 1 Characteristics of study participants

\begin{tabular}{|c|c|c|c|c|c|c|}
\hline & Overall & Kenya & Uganda & Burkina Faso & The Gambia & South Africa \\
\hline No. of participants (\%) & 4509 (100\%) & $1361(30.1 \%)$ & $1301(28.9 \%)$ & $329(7.3 \%)$ & $629(13.9 \%)$ & $889(19.7 \%)$ \\
\hline Median 25(OH)D nmol/L (IQR) ${ }^{\mathrm{a}}$ & $77.6(63.6,94.2)$ & $81.0(66.3,101.6)$ & $78.6(65.1,94.5)$ & $78.4(64.5,91.3)$ & $71.2(59.1,84.2)$ & $76.2(60.6,91.9)$ \\
\hline \multicolumn{7}{|l|}{ Vitamin D status } \\
\hline $25(\mathrm{OH}) \mathrm{D}>150 \mathrm{nmol} / \mathrm{l}$ & $79 / 4509$ (1.8\%) & $51 / 1361(3.7 \%)$ & $17 / 1301(0.1 \%)$ & $4 / 329(1.3 \%)$ & $1 / 629(0.2 \%)$ & 6/889 (0.7\%) \\
\hline $25(\mathrm{OH}) \mathrm{D}>75 \mathrm{nmol} / \mathrm{l}$ & $2485 / 4509(55.1 \%)$ & $815 / 1361$ (59.9\%) & 756/1301 (58.1\%) & 186/329 (56.5\%) & 265/629 (42.1\%) & $463 / 889(52.1 \%)$ \\
\hline 25(OH)D 50-75 nmol// & $1674 / 4509$ (37.1\%) & 464/1361 (34.1\%) & 479/1301 (36.8\%) & $123 / 329(37.4 \%)$ & $302 / 629(48.0 \%)$ & $306 / 889(34.4 \%)$ \\
\hline $25(\mathrm{OH}) \mathrm{D}<50 \mathrm{nmol} / \mathrm{l}$ & $350 / 4509(7.8 \%)$ & $82 / 1361(6.0 \%)$ & 66/1301 (5.1\%) & 20/329 (6.1\%) & $62 / 629(9.9 \%)$ & $120 / 889(13.5 \%)$ \\
\hline $25(\mathrm{OH}) \mathrm{D}<30 \mathrm{nmol} / \mathrm{l}$ & 28/4509 (0.6\%) & 4/1361 (0.3\%) & 5/1301 (0.4\%) & 0/329 (0\%) & $2 / 629(0.3 \%)$ & $17 / 889(1.9 \%)$ \\
\hline Median age (months) & $23.9(12.3,35.9)$ & $19.8(12.7,36.8)$ & $24.1(23.9,35.9)$ & $23.4(19.7,26.4)$ & $46.6(35.2,58.7)$ & $12.0(11.9,12.1)$ \\
\hline \multicolumn{7}{|l|}{ Age categories (months) } \\
\hline$<12$ & $816 / 4509$ (18.1\%) & 300/1361 (22.0\%) & 24/1301 (1.8\%) & 19/329 (5.8\%) & - & $473 / 889(53.2 \%)$ \\
\hline $12-24$ & $1597 / 4509$ (35.4\%) & 555/1361 (40.8\%) & 440/1301 (33.8\%) & $172 / 329(52.3 \%)$ & $15 / 629(2.4 \%)$ & $415 / 889(46.7 \%)$ \\
\hline $24-36$ & $1029 / 450(22.8 \%)$ & 153/1361 (11.2\%) & 587/1301 (45.1\%) & 138/329 (42.0\%) & 150/629 (23.9\%) & $1 / 889(0.1 \%)$ \\
\hline $36-48$ & $478 / 4509(10.6 \%)$ & 146/1361 (10.7\%) & 167/1301 (11.8\%) & - & $165 / 629(26.2 \%)$ & - \\
\hline $48+$ & $589 / 4509(13.1 \%)$ & 207/1361 (15.2\%) & $83 / 1301$ (6.4\%) & - & 299/629 (47.5\%) & - \\
\hline Sex: females & $2216 / 4509$ (49.1\%) & 671/1361 (49.3\%) & 641/1301 (49.3\%) & 161/329 (48.9\%) & 297/629 (47.2\%) & $446 / 889(50.2 \%)$ \\
\hline \multicolumn{7}{|l|}{ Season $^{\mathrm{eb}}$} \\
\hline Summer/short rains/dry & $867 / 4503(19.3 \%)$ & 285/1361 (20.9\%) & $331 / 1296(25.5 \%)$ & $72 / 329$ (21.9\%) & - & 179/889 (18.1\%) \\
\hline Autumn/dry & 1475/4503 (32.8\%) & $896 / 1361$ (65.8\%) & 295/1296 (22.8\%) & 123/329 (37.4\%) & - & $161 / 889(18.1 \%)$ \\
\hline Winter/long rains & $1361 / 4503(30.2 \%)$ & $86 / 1361$ (6.3\%) & $330 / 1296(25.5 \%)$ & 129/329 (39.2\%) & $536 / 628(85.4 \%)$ & $280 / 889(31.5 \%)$ \\
\hline Spring/dry & $800 / 4503(17.8 \%)$ & $94 / 1361$ (6.9\%) & $340 / 1296(26.2 \%)$ & $5 / 329(1.5 \%)$ & $92 / 628(14.7 \%)$ & 269/889 (30.3\%) \\
\hline \multicolumn{7}{|l|}{ Nutritional status $^{\complement}$} \\
\hline Stunted & $581 / 2289(25.4 \%)$ & $99 / 208$ (47.6\%) & 203/1282 (15.8\%) & 103/307 (33.5\%) & 176/492 (35.8\%) & $\mathrm{n} / \mathrm{a}$ \\
\hline Underweight & 389/2487 (15.6\%) & 102/389 (26.2\%) & 103/1296 (8.0\%) & $58 / 309$ (18.8\%) & 126/493 (25.6\%) & $\mathrm{n} / \mathrm{a}$ \\
\hline Wasted & 147/2285 (6.4\%) & 24/205 (11.7\%) & $59 / 1281$ (4.6\%) & 20/307 (6.5\%) & 44/492 (8.9\%) & $\mathrm{n} / \mathrm{a}$ \\
\hline Inflammation ${ }^{d}$ & $1019 / 4469$ (22.8\%) & $363 / 1344$ (27.0\%) & 306/1285 (23.8\%) & 109/322 (33.9\%) & $85 / 629$ (13.5\%) & 156/889 (17.6\%) \\
\hline Malaria $^{e}$ & 445/3293 (13.5\%) & 227/1082 (20.8\%) & $89 / 1280$ (7.0\%) & 64/303 (21.1\%) & 65/628 (10.4\%) & $\mathrm{n} / \mathrm{a}$ \\
\hline
\end{tabular}

South African children were not exposed to malaria

$I Q R$ inter-quartile range, $n / a$ not available, $25(\mathrm{OH}) \mathrm{D} 25$-hydroxyvitamin $\mathrm{D}$

${ }^{a}$ Medians (interquartile ranges) are presented. 'b Seasons were based on 3 monthly intervals: 1st season, December to February; 2 nd season, March to May; 3rd season, June to August; 4th season, September to November. In South Africa, the seasons correspond to summer, autumn, winter and spring, respectively, in Uganda and Kenya there are two rainy and two dry seasons and in Burkina Faso and The Gambia there is a single rainy and dry season. However, timing of the rains is often unpredictable and may vary from these times. 'Stunted was defined as height-for-age $Z$ score $<-2$; underweight as weight-for-age $Z$ score $<-2$, wasted as weight-for-height $Z$ score $<-2$ (denominator number varied because anthropometry data was not available for South African children). Inflammation as CRP $>5 \mathrm{mg} / \mathrm{L}$ or $\mathrm{ACT}>0.6 \mathrm{~g} / \mathrm{L}$. ACT, but not CRP, was available for The Gambia. ${ }^{\mathrm{e}}$ Malaria as the presence of $P$. falciparum parasites on blood film 
prevalence of vitamin D deficiency varied by country, with the highest prevalence observed in South African children (Table 1 and Fig. 1). About 1.8\% (79/4509) of children had 25(OH)D levels above $150 \mathrm{nmol} / \mathrm{L}$ (51 Kenyan, 17 Ugandan, four Burkinabe, one Gambian and six South African children).

\section{Vitamin D status is associated with age and season, but not with nutritional status}

25(OH)D levels decreased with increasing age across all age groups (Additional file 3: Table S2 and Additional file 10: Figure S2), even after adjustment for potential confounders in multivariable regression analyses (Table 2). Approximately $4.5 \%$ of the observed variation $\left(R^{2}=0.045\right)$ in $25(\mathrm{OH}) \mathrm{D}$ levels was explained by age (Table 2). In a multivariable linear regression analysis, study site, age, sex, season and inflammation accounted for $12 \%\left(R^{2}=0.12\right)$ of observed variation in $25(\mathrm{OH}) \mathrm{D}$ levels. Each additional year of age increased the odds of 25(OH)D levels < 50 and 50$75 \mathrm{nmol} / \mathrm{L}$ by $69 \%$ (OR 1.69, [95\% CI 1.52, 1.89]) and $43 \%$ (OR 1.43, [95\% CI 1.34, 1.52]), respectively (Additional file 4: Table S3). Vitamin D deficiency $(25(\mathrm{OH}) \mathrm{D}<50$ $\mathrm{nmol} / \mathrm{L}$ ) was more prevalent during the South African winter and the long rains in sub-Saharan Africa (Fig. 1 and Additional file 4: Table S3). Seasonality explained $3.8 \%$ of the variation in $25(\mathrm{OH}) \mathrm{D}$ levels $\left(R^{2}=0.038\right)$ (Table 2).

Median 25(OH)D levels were lower in stunted children in univariable analyses, but this association was not observed after adjustment for potential confounding factors in multivariable regression models (Table 2). Overall $25(\mathrm{OH}) \mathrm{D}$ levels were not associated with sex, underweight or wasting although girls had a $32 \%$ higher risk of 25(OH)D levels of $<50 \mathrm{nmol} / \mathrm{L}$ (Table 2 and Fig. 1), a finding that was mainly observed in The Gambia. Findings are presented by individual countries in Additional file 3: Tables S2, Additional file 4: Table S3, Additional file 5: Table S4 and Additional file 6: Table S5.

\section{5(OH)D levels are higher with inflammation and lower with malaria}

Children with inflammation (CRP $>5 \mathrm{mg} / \mathrm{L}$ or ACT > $0.6 \mathrm{~g} / \mathrm{L})$ had higher median 25(OH)D levels $(81.9 \mathrm{nmol} / \mathrm{L}$ [IQR 68.0, 99.5]) than those without inflammation (76.4 nmol/L [IQR 62.7, 92.3])) (Table 2 and Additional file 10: Figure S2), a difference that was observed in all countries except Burkina Faso (Additional file 3: Table S2). Inflammation explained $1.2 \%\left(R^{2}=0.012\right)$ of the total variation in $25(\mathrm{OH}) \mathrm{D}$ levels (Table 2). Children with inflammation were $42 \%$ and $26 \%$ less likely to have $25(\mathrm{OH}) \mathrm{D}$ levels of $<50$ and $50-75 \mathrm{nmol} / \mathrm{L}$, respectively, compared to those with 25(OH)D levels $>75 \mathrm{nmol} / \mathrm{L}$ (Additional file 4: Table S3). CRP levels also varied by country (Additional file 11: Figure S3).
Children with asymptomatic malaria parasitaemia had lower median 25(OH)D levels $(71.3 \mathrm{nmol} / \mathrm{L}$ [IQR 58.9, 85.4]) than those without $(77.1 \mathrm{nmol} / \mathrm{L}$ (IQR 63.1, 92.4) (Table 2 and Additional file 10: Figure S2). Malaria was further associated with lower vitamin D status in multivariable regression analyses adjusted for potential confounders, although this association was observed only in Kenya (Table 2, Additional file 4: Table S3 and Additional file 6: Table S5). Malaria parasitaemia explained $0.4 \%$ of variation in $25(\mathrm{OH}) \mathrm{D}$ levels $\left(\mathrm{R}^{2}=0.004\right)$ (Table 2).

\section{Vitamin D binding protein variants are associated with vitamin D status}

Overall, the most frequent DBP haplotype was Gc1f/f (69.8\%), followed by Gc1f/2 (13.6\%), Gc1f/s (13.4\%), Gc1s/2 (1.7\%), Gc1s/s (1.0\%), and least frequent was Gc2/2 (0.6\%) (Table 3). The most frequent Gc variant was Gc1f (83.3\%), followed by Gc1s (8.5\%), and the least frequent was Gc2 (8.2\%). Frequencies of DBP haplotypes and variants varied by country, with the highest frequencies of Gc1f, Gc1s and Gc2 observed in South Africa (87.3\%), The Gambia (13.1\%) and Uganda (10.2\%), respectively (Additional file 7: Table S6). Median 25(OH)D levels were lowest in children carrying the Gc2 variant $(72.4 \mathrm{nmol} / \mathrm{L}$ [IQR 59.4, 86.5]), but did not differ between the Gc1f (77.3 nmol/L [IQR 63.5, 92.8]) and Gc1s variants $(78.9 \mathrm{nmol} / \mathrm{L}[63.8,95.5])$. Median 25(OH)D levels similarly differed by DBP haplotype (Table 3). DBP haplotypes and variants explained $0.9 \%$ and $0.4 \%$ of the variation in $25(\mathrm{OH}) \mathrm{D}$ levels, respectively (Table 3 ). The Gc2 variant was associated with lower $25(\mathrm{OH}) \mathrm{D}$ levels $(\beta=-0.08$ [95\% CI $-0.11,-0.06$ ] and a 69\% (OR $1.69[1.23,2.31])$ increased risk of vitamin $\mathrm{D}$ deficiency $(25(\mathrm{OH}) \mathrm{D}$ levels $<50 \mathrm{nmol} / \mathrm{L})$ in adjusted regression analyses (Table 3). The Gc2 variant was similarly associated with the highest prevalence of vitamin D deficiency (Fig. 1). Country-specific analyses are presented in Additional file 7: Table S6).

\section{Meta-analysis}

Out of 18 previous studies that assessed the vitamin D status of African children aged 0-8 years (Additional file 8: Table S7), we included a total of 12 studies in the meta-analyses. Six studies were excluded because they lacked estimates of mean 25(OH)D levels, prevalence of vitamin D status $(25(\mathrm{OH}) \mathrm{D}<50$ or $<75 \mathrm{nmol} / \mathrm{L})$ or did not report estimates from children aged between 0 and 8 years. The meta-analyses included 2128 children from five African countries with mean ages ranging from one to 47 months and included estimates from healthy children in 9 case-control and three population-based studies in addition to the current study. Overall, mean $25(\mathrm{OH}) \mathrm{D}$ level in young African children was $73.2 \mathrm{nmol} /$ 


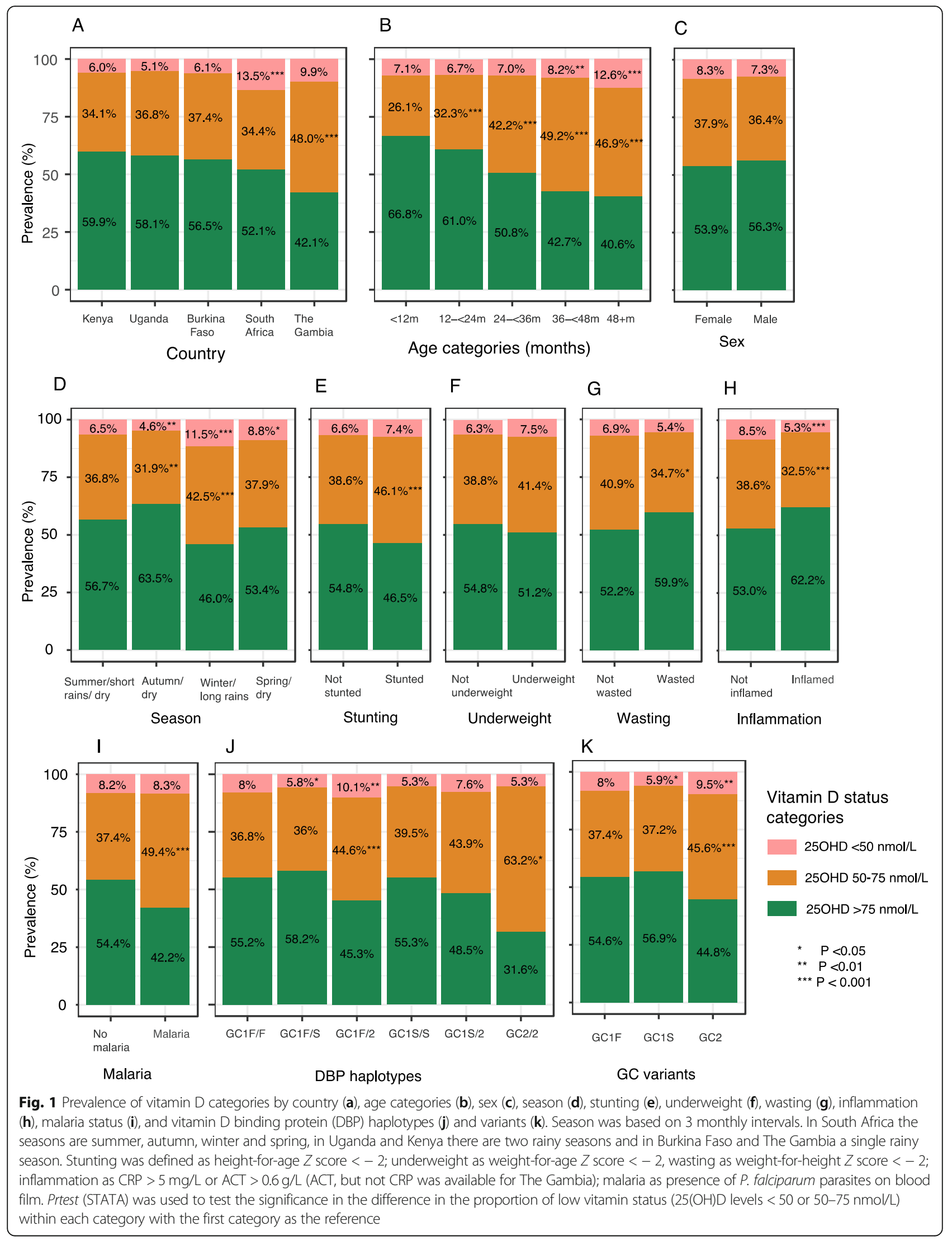




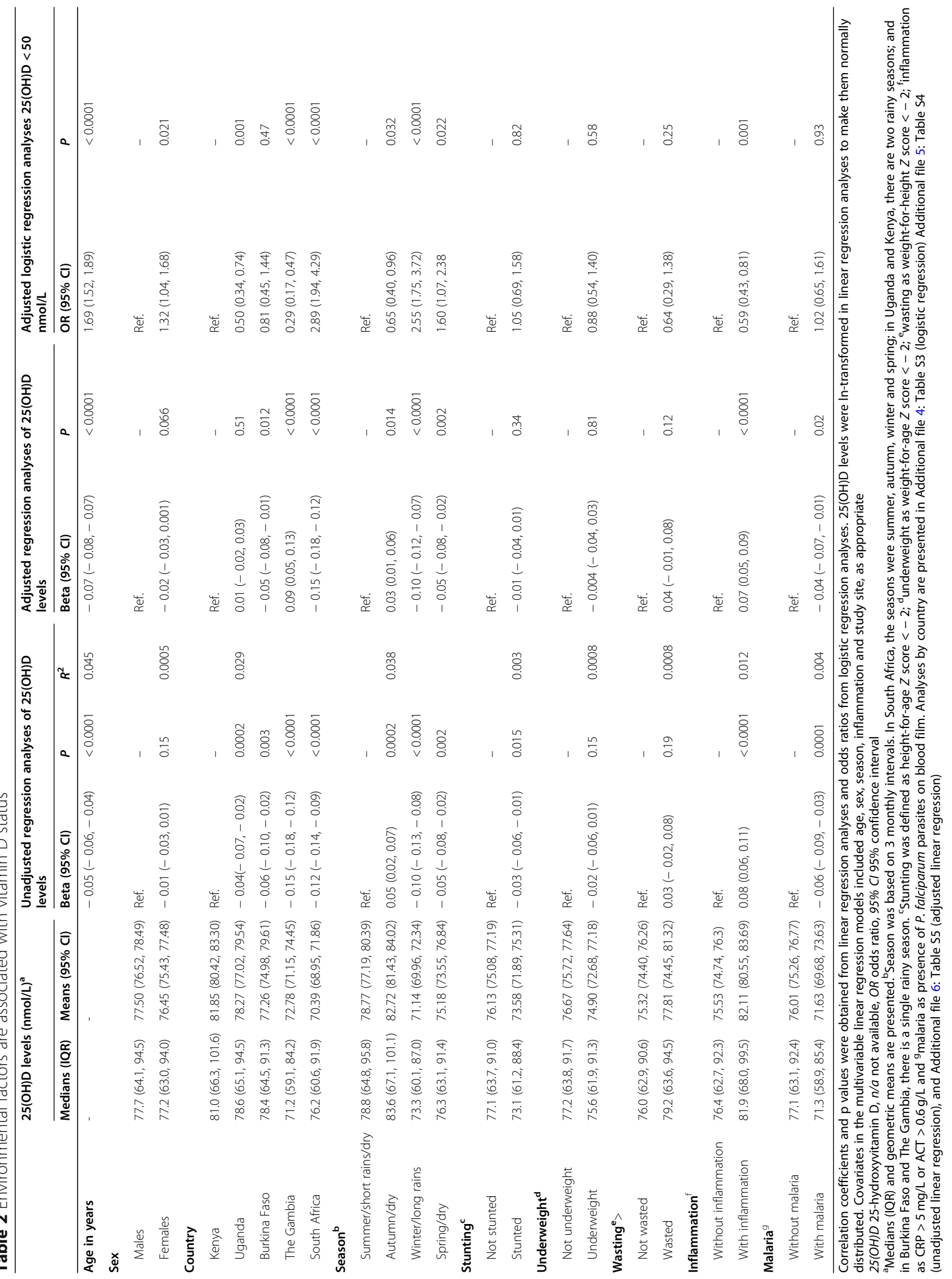




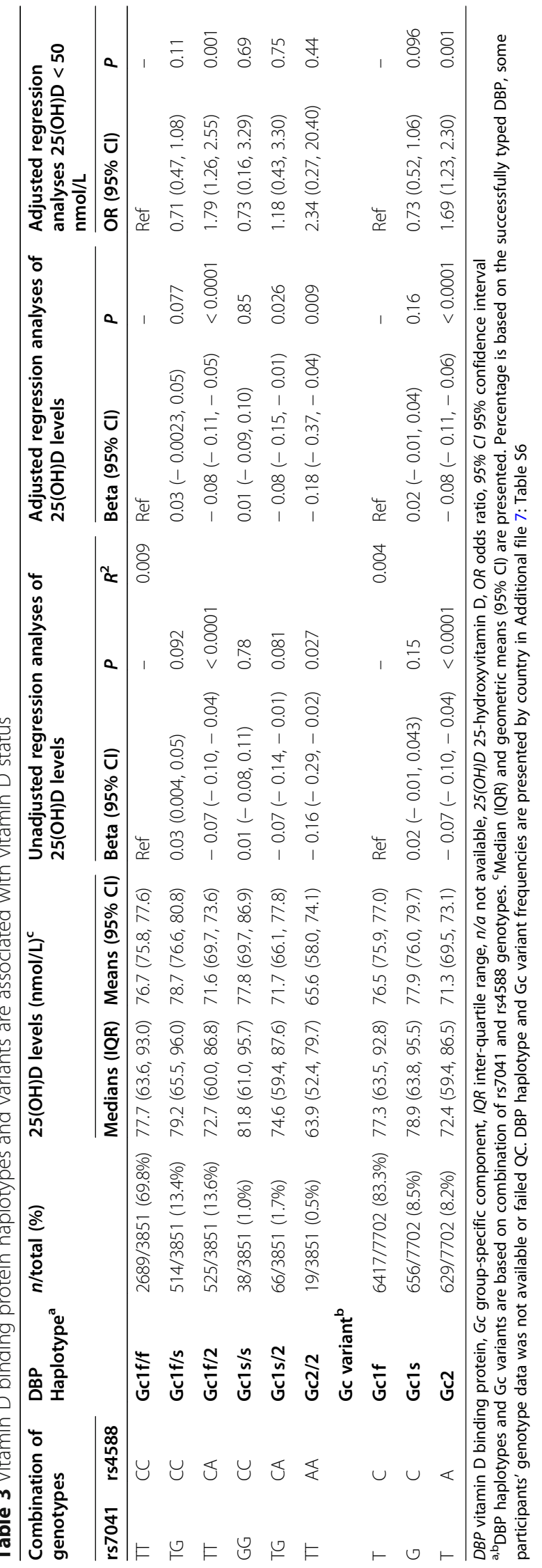




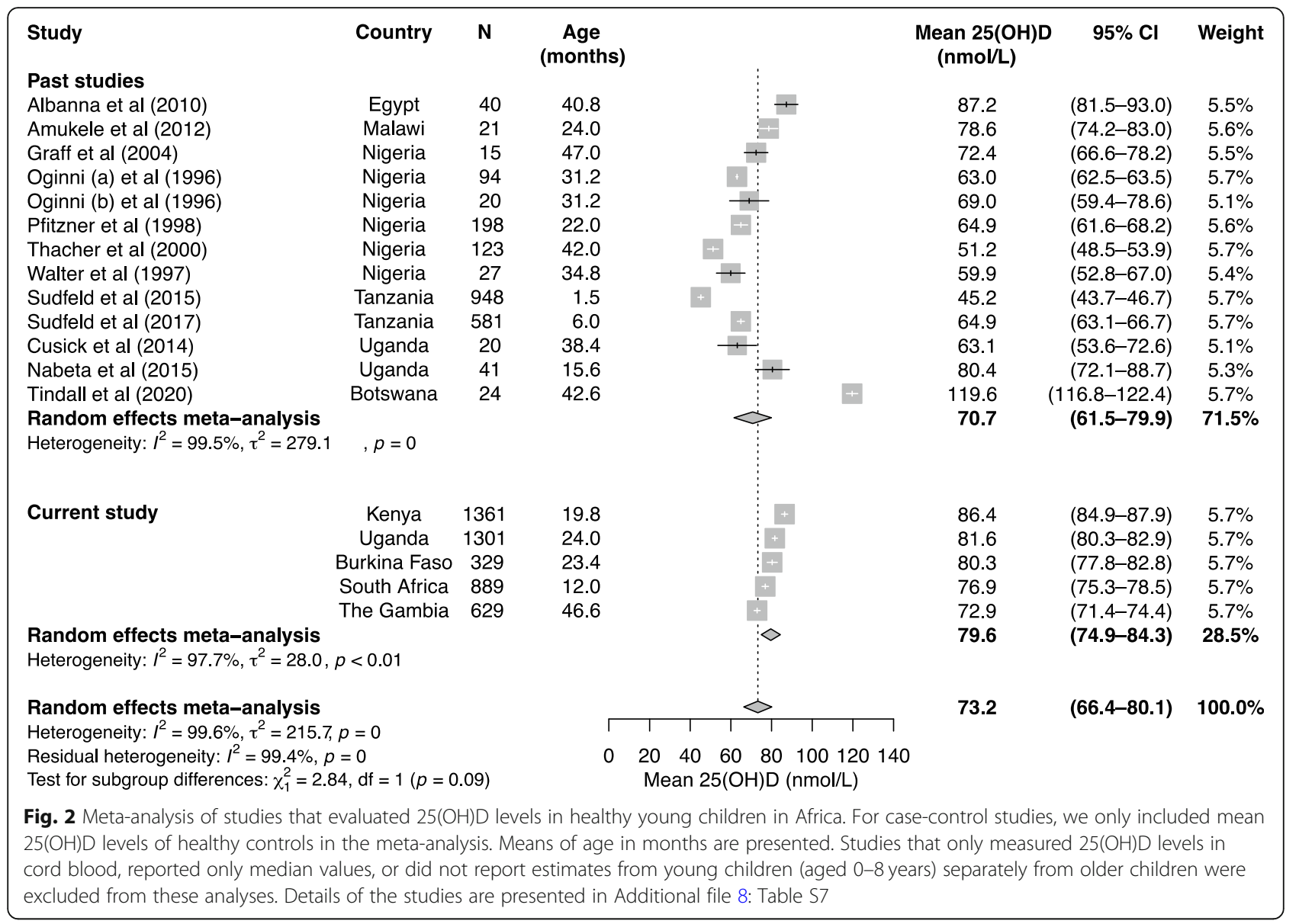

L (95\% CI 66.4, 80.1) (Fig. 2) and prevalence of $25(\mathrm{OH}) \mathrm{D}$ levels $<50$ and $<75 \mathrm{nmol} / \mathrm{L}$ was $10.9 \%(95 \%$ CI $6.9,15.5)$ and $49.1 \%(95 \%$ CI 40.8, 57.5), respectively (Additional file 12: Figure S4 and Additional file 13: Figure S5). Only a single eligible study reported prevalence defined by $25(\mathrm{OH}) \mathrm{D}$ levels $<30 \mathrm{nmol} / \mathrm{L}$ [4] precluding meta-analysis. There was high heterogeneity between studies included in the meta-analyses with overall $I^{2}$ ranging from $95.1 \%$ and $99.4 \%(p<0.01)$.

\section{Discussion}

Little is known about the vitamin D status of African children. In this study, overall median 25(OH)D level was $77.6 \mathrm{nmol} / \mathrm{L}$ (IQR 63.6, 94.2) and prevalence of $25(\mathrm{OH}) \mathrm{D}$ cut-offs between 50 and $75,<50$, and $<30$ $\mathrm{nmol} / \mathrm{L}$ was $37.1 \%, 7.8 \%$, and $0.6 \%$, respectively, in young African children. The prevalence of vitamin D deficiency $(25(\mathrm{OH}) \mathrm{D}$ levels $<50 \mathrm{nmol} / \mathrm{L})$ was higher in South African children and during the South African winter or the long rainy season in East Africa. Median 25(OH)D levels decreased with increasing age and with inflammation but did not differ by sex or nutritional status after adjustment for potential confounders in multivariable models. Malaria parasitaemia was associated with lower
25(OH)D levels overall and in Kenyan children, but not in Ugandan, Burkinabe or Gambian children. The most common Gc variant was Gc1f (83.3\%), followed by Gc1s (8.5\%) and $\mathrm{Gc} 2$ (8.2\%), with $\mathrm{Gc} 2$ being associated with the lowest $25(\mathrm{OH}) \mathrm{D}$ levels and the highest prevalence of low vitamin D status $(25(\mathrm{OH}) \mathrm{D}$ levels $<50$ and 50-75 $\mathrm{nmol} / \mathrm{L})$. In a meta-analysis of the current and previous studies of young African children overall mean 25(OH)D level was $73.2 \mathrm{nmol} / \mathrm{L}$.

Our median $25(\mathrm{OH}) \mathrm{D}$ estimate of $77.6 \mathrm{nmol} / \mathrm{L}$ is comparable to values reported in previous studies of healthy young children in sub-Saharan Africa including reported levels of $80.4 \mathrm{nmol} / \mathrm{L}$ in Uganda, $78.6 \mathrm{nmol} / \mathrm{L}$ in Malawi, and $72.4 \mathrm{nmol} / \mathrm{L}$ in Nigeria (Fig. 2). However, studies in 198 Nigerian children and 581 Tanzanian infants living in urban areas reported lower mean levels of 64.8 and $64.9 \mathrm{nmol} / \mathrm{L}$, respectively $[8,9]$. The prevalence of vitamin D deficiency $(25(\mathrm{OH}) \mathrm{D}$ levels $<50 \mathrm{nmol} / \mathrm{L})$ was $7.8 \%$ overall, with a higher prevalence of $13.5 \%$ in South Africa. Previous studies of healthy young children have reported higher prevalence estimates of $13.6 \%$ in Kenya, $15.0 \%$ in Uganda, and $25.8 \%$ in Nigeria $[4,8,15]$. Prevalence estimates were also higher in young children from other continents, including estimates of $15 \%$ in the USA, 
$14 \%$ in Japan, and $11 \%$ in China [34-36]. Vitamin D deficiency is also more prevalent in northern African countries [2], and the higher vitamin D status observed in our study might be explained by differences in latitude, geography, skin pigmentation, clothing coverage, and religious and cultural practices across Africa [37]. The year-round abundance of sunshine in sub-Saharan Africa may also explain higher vitamin D status although vitamin D supplementation and food fortification is less common. Since vitamin D deficient rickets is rare at levels above $30 \mathrm{nmol} / \mathrm{L}$, the very low prevalence of $25(\mathrm{OH}) \mathrm{D}$ levels $<30 \mathrm{nmol} / \mathrm{l}(0.6 \%)$ in the current study suggests that rickets in African children is more likely to be caused by calcium rather than vitamin $\mathrm{D}$ deficiency. Conversely, we found very few children with $25(\mathrm{OH}) \mathrm{D}$ levels above $150 \mathrm{nmol} / \mathrm{L}$ suggesting that even plenty of exposure to sunlight rarely generates these high levels probably because vitamin $\mathrm{D}$ production in the skin is highly regulated [1].

In the present study, 25(OH)D levels decreased consistently with age overall and in all countries except The Gambia (Additional file 3: Table S2), perhaps because of older age in the Gambian children and corresponding cultural habits. Age explained $4.5 \%$ of the variation in 25(OH)D levels. Previous studies of school children (aged 5-18 years) from South Africa, Ethiopia and Algeria have also reported that 25(OH)D levels decreased with age $[11,38,39]$. However, a single study in Malawian pre-school children reported an increase in 25(OH)D levels with age; however, this study was small $(n=21)$ and included infants of mothers living with HIV in Malawi [6]. Studies from high-income countries have reported an increase in 25(OH)D levels with age, but children in these studies received vitamin D supplementation or fortification $[34,35,40]$. In a meta-analysis of previous studies from Africa, children had higher vitamin D status than adults in African populations [2] possibly due to increased time spent outdoors.

In addition, we found limited evidence of an association between 25(OH)D levels and sex, although overall girls had a $32 \%(95 \%$ CI 1.04, 1.68) increased risk of vitamin D deficiency $(25(\mathrm{OH}) \mathrm{D}<50 \mathrm{nmol} / \mathrm{L})$ compared to boys. Similar studies from South Africa, China, and Ecuador have not found sex-related differences in 25(OH)D levels [36, 38, 41]. We also found evidence of seasonality in $25(\mathrm{OH}) \mathrm{D}$ levels with the strongest effect in South Africa, and more variable effects observed across the sub-Saharan African countries during the rainy season. These findings may be explained by colder winters in South Africa with greater coverage of skin by clothing and more time spent indoors and in East Africa by increased cloud cover and less time spent outdoors during the long rains. Season explained 3.8\% of the variation in $25(\mathrm{OH}) \mathrm{D}$ levels. These findings agree with previous studies that evaluated the effect of seasonality in vitamin $D$ status in Africa, although many of these studies were in South Africa or northern African countries [2].

We did not find associations between 25(OH)D levels and stunting, underweight, or wasting in adjusted regression analyses. Similarly, studies in young children from Tanzania $(n=948)$ and Nepal $(n=280)$ reported that $25(\mathrm{OH}) \mathrm{D}$ levels were not associated with stunting, underweight or wasting [10, 42]. However, severe wasting was associated with $25(\mathrm{OH}) \mathrm{D}$ levels $<30 \mathrm{nmol} / \mathrm{L}$ in 21 Kenyan children with rickets [4]. In addition, Mokhtar and colleagues reported that low 25(OH)D levels $(<42.5 \mathrm{nmol} / \mathrm{L})$ were more common among stunted and underweight Ecuadorian children [41]. The lack of association between vitamin D status and anthropometric indices in the current study suggests that sunlight may be more important than dietary intake in influencing vitamin D status in Africa.

We observed a positive correlation between $25(\mathrm{OH}) \mathrm{D}$ levels and markers of inflammation overall and children with inflammation had higher $25(\mathrm{OH}) \mathrm{D}$ levels than those without after adjusting for potential confounders. Our findings agree with results from a small casecontrol study in Egyptian children with sepsis $(n=40$, mean age 6 years) and a large community-based study of children ( $n=4274$, mean age 9.9 years $)$ in England, which reported that $25(\mathrm{OH}) \mathrm{D}$ levels increased with increasing levels of CRP and IL-6 $[7,13]$. In contrast, a recent meta-analysis of 24 randomised controlled trials reported that vitamin D supplementation had an overall effect of reducing IL6, but not CRP or other inflammatory markers, although many trial participants had medical conditions [14]. A nationally representative survey of 15,167 adults in the USA reported an inverse association between 25(OH)D and CRP levels at 25(OH)D levels < $52 \mathrm{nmol} / \mathrm{L}$ and a positive association above this level [43], suggesting that there may be a U-shaped association, which might explain previously mixed findings. In our study, $90 \%$ of children had 25(OH)D levels $>52$ $\mathrm{nmol} / \mathrm{L}$, perhaps explaining the positive association observed between inflammation and $25(\mathrm{OH}) \mathrm{D}$ levels. However, the association between inflammation and $25(\mathrm{OH}) \mathrm{D}$ may not be clinically relevant since inflammation explained only $1.2 \%$ of the observed variation in 25(OH)D levels.

In this study, 25(OH)D levels between 50 and 75 $\mathrm{nmol} / \mathrm{L}$ were associated with an increased risk of afebrile malaria parasitaemia overall compared to levels $>75$ $\mathrm{nmol} / \mathrm{L}$. In contrast, a study in western Kenya found no association between $25(\mathrm{OH}) \mathrm{D}$ levels and malaria parasitaemia in newborns and their mothers [44]. However, another study in Uganda reported that children with severe malaria had lower 25(OH)D levels than healthy 
community children [15]. Malaria explained only $0.4 \%$ of the variation in $25(\mathrm{OH}) \mathrm{D}$ levels in our study, suggesting that this association may not be clinically significant. No clinical trials have yet investigated the effect of vitamin D supplementation on malaria incidence or treatment outcomes [45].

In the current study, we found that Gc1f was the most frequent Gc variant (83.3\%) and the Gc1s and Gc2 variants were less frequent (8.5 and 8.2\%, respectively). The Gc1f and Gc1s variants were associated with higher $25(\mathrm{OH}) \mathrm{D}$ levels compared to the Gc2 variant. In agreement with our study, a study involving 237 Gambian children with similar Gc variant frequencies (Gc1f was $86 \%$, Gc1s $11 \%$ and Gc2 3\%) reported that Gc1f was associated with higher $25(\mathrm{OH}) \mathrm{D}$ levels than the other haplotypes combined [19]. Gc1f, the most frequent Gc variant in Africans, has a higher binding affinity for vitamin D compared to the Gc1s and Gc2 variants which are more frequent in Europeans and Asians $[16,18]$. In a study involving adults from The Gambia and the UK $(n=36)$, Gc1f was associated with higher total $25(\mathrm{OH}) \mathrm{D}$ levels and shorter 25(OH)D half-life [20]. In addition, DBP levels and genetic polymorphisms have been linked to lower levels of $25(\mathrm{OH}) \mathrm{D}$ in black American adults compared with white American adults [17]. In another study involving multi-ethnic children, differences in DBP polymorphisms were associated with lower vitamin D status in African children and reduced response to vitamin D intake compared to Hispanic and Caucasian children [46]. The differences in 25(OH)D levels attributed to DBP polymorphism has led to the suggestion that DBP variants and levels should be considered in the assessment of vitamin D status in different populations [47].

\section{Strengths and limitations}

To the best of our knowledge, the current study, which included a total of 4509 children, is the largest study to date to evaluate vitamin D status and its predictors in young African children. The study further evaluated the effect of common genetic polymorphisms encoding the vitamin D binding protein on 25(OH)D levels. However, our findings should be interpreted in the context of some limitations. First, due to the cross-sectional nature of our study, we could not evaluate temporal changes in 25(OH)D and CRP levels or infer the direction of causality for the observed associations. We also did not measure vitamin $\mathrm{D}$ binding protein, parathyroid hormone, calcium levels, dietary or supplementary vitamin D intake, or exposure to sunlight, factors which have been shown to influence vitamin $\mathrm{D}$ status. DBP may also be a better marker of the effect of inflammation since it is reduced during tissue damage and in inflammation resulting in the reduction of circulating $25(\mathrm{OH}) \mathrm{D}$ levels and other vitamin D metabolites [48]. Our study cohorts were also diverse with different ethnicities and ages, and hence may not be generalisable to other age groups or African countries, although cohort-specific data and analyses were presented.

\section{Conclusions}

Approximately $0.6 \%$ and $7.8 \%$ of children in our study had 25(OH)D levels of $<50$ or $<30 \mathrm{nmol} / \mathrm{L}$, and approximately one third of children had $25(\mathrm{OH}) \mathrm{D}$ levels between 50 and $75 \mathrm{nmol} / \mathrm{L}$. Our data indicate that older children and those who live further from the equator may be at a higher risk of vitamin D deficiency. Stunting, underweight and wasting were not associated with vitamin D deficiency suggesting that sunlight is a more important source of vitamin $D$ than dietary intake in children living in sub-Saharan Africa. Genetic differences in DBP also altered 25(OH)D levels. Further research is required to understand the effects of inflammation and malaria on vitamin D status in Africa and to investigate the causality between vitamin D status and infectious diseases like malaria, which are common in African children. These findings may have important implications for public health strategies involving young children in Africa.

\section{Abbreviations}

25(OH)D: 25-hydroxyvitamin D; CRP: C-reactive protein; EMaBS: Entebbe Mother and Baby Study; HAZ: Height-for-age z-scores; WAZ: Weight-for-age z-scores; WHZ: Weight-for-height z-scores; DBP: Vitamin D binding protein

\section{Supplementary Information}

The online version contains supplementary material available at https://doi. org/10.1186/s12916-021-01985-8.

Additional file 1: Supplementary methods. (Genotyping and SNP quality control). This file describes the methods used in genotyping and SNP quality control, QC parameters, allocation of vitamin D binding protein Gc variants and haplotypes.

Additional file 2: Table S1. Databases search keywords. This table includes keywords used systematically search PubMed and Embase for articles of studies that measured vitamin D status in young children.

Additional file 3: Table S2. Median 25(OH)D levels by study variable in each country. This is a table of median $25(\mathrm{OH}) \mathrm{D}$ levels for each study variable in each country.

Additional file 4: Table S3. Multivariable logistic regression analyses of factors associated with low vitamin D status in each country. This is a table showing odd ratios (with their corresponding 95\% Cls and $\mathrm{p}$ values) from multivariable logistic regression analyses.

Additional file 5: Table S4. Univariable linear regression of 25(OH)D concentrations by study variables in each country. This is a table of univariable linear regression coefficients (with 95\% Cl) and $p$ values presented by country.

Additional file 6: Table S5. Multivariable regression of 25(OH)D concentrations by study variables in each country. This is a table of multivariable linear regression coefficients (with 95\% Cl) and p values presented by country.

Additional file 7: Table S6. Median 25(OH)D levels by vitamin D binding protein haplotype and Gc variant in each country. This is a table 
of DBP variant and haplotype frequencies and median 25(OH)D levels by country.

Additional file 8: Table S7. Summary characteristics of studies that evaluated the vitamin D status of African children (in alphabetical order). This is a table describing characteristics of past studies that evaluated the vitamin D status of young children in Africa.

Additional file 9: Figure S1. The precision profile of the $25(\mathrm{OH}) \mathrm{D}$ assay. This is a scatter plot of coefficient of variation (\%) of the $25(\mathrm{OH}) \mathrm{D}$ assay used in this study.

Additional file 10: Figure S2. Boxplots of 25(OH)D concentrations by country (A), age categories (B), sex (C), season (D) stunting (E), underweight $(\mathrm{F})$, wasting $(\mathrm{G})$, inflammation $(\mathrm{H})$, malaria $(\mathrm{I})$, vitamin $\mathrm{D}$ binding protein (DBP) isotype $(J)$ and $G c$ variant $(K)$. This is a grid of boxplots of 25(OH)D concentrations for each study variable.

Additional file 11: Figure S3. Boxplots of CRP levels overall and by country. These are boxplots of CRP levels.

Additional file 12: Figure S4. Meta-analysis of studies that estimated the prevalence of $25(\mathrm{OH}) \mathrm{D}$ levels $<50 \mathrm{nmol} / \mathrm{L}$ in healthy children aged $0-8$ years in Africa. This is a meta-analysis plot of prevalence estimates of vitamin D deficiency (defined by $25(\mathrm{OH}) \mathrm{D}$ levels $<50 \mathrm{nmol} / \mathrm{L}$ ) in young children included in the current and previous studies.

Additional file 13: Figure S5. Meta-analysis of studies that estimated the prevalence of $25(\mathrm{OH}) \mathrm{D}$ levels $<75 \mathrm{nmol} / \mathrm{L}$ in healthy children aged $0-8$ years in Africa. This is a meta-analysis plot of prevalence estimates of low vitamin D status (defined by $25(\mathrm{OH}) \mathrm{D}$ levels $<75 \mathrm{nmol} / \mathrm{L}$ ) in young children included in the current and previous studies.

\section{Acknowledgements}

We thank colleagues at the KEMRI-Wellcome Trust Research Programme, Jedidah Mwacharo and Barnes Kitsao for assistance in retrieval of archived samples. We also thank the teams at the UVRI/MRC Entebbe Mother and Baby Study, the Malaria Vectored Vaccines Consortium (MVC) in Burkina Faso, and the Respiratory and Meningeal Pathogens Unit (RMPRU) in Johannesburg, South Africa. We thank the Oxford Genomics Centre at the Wellcome Centre for Human Genetics (funded by Wellcome Trust grant reference 203141/Z/16/Z) for the generation and initial processing of the sequencing data for samples from Kenya and The Gambia. This study is published with the permission of the Office of the Director of KEMRI.

\section{Authors' contributions}

RMM, TNW, AA and SHA conceived and designed the study. Data was obtained by all the authors and was analysed by RMM, JMM, and SHA. RMM and SHA wrote the first draft of the manuscript. RMM, JMM, AJM, EMW, WK, AWM, FMN, CC, SBS, AD, ABT, SAL, AM, SAM, AMP, MSS, PB, JMP, AME, AA, TNW, SHA contributed to data interpretation, reviewed successive drafts and approved the final version of the manuscript. The sponsors played no role in study design, data collection, data analysis, data interpretation or writing of the report.

\section{Funding}

This work was funded by Wellcome [grant numbers SHA 110255, TNW 202800, AJM 106289 and AME 064693, 079110, 095778], and with core awards to the KEMRI-Wellcome Trust Research Programme [203077]. AA is supported by the Intramural Research Program of the National Institutes of Health in the Center for Research on Genomics and Global Health (CRGGH). The CRGGH (1ZIAHG200362) is supported by the National Human Genome Research Institute, the National Institute of Diabetes and Digestive and Kidney Diseases, the Center for Information Technology, and the Office of the Director at the National Institutes of Health. RMM is supported through the Developing Excellence in Leadership, Training and Science (DELTAS) Africa Initiative [DEL-15-003]. The DELTAS Africa Initiative is an independent funding scheme of the African Academy of Sciences (AAS)'s Alliance for Accelerating Excellence in Science in Africa (AESA) and supported by the New Partnership for Africa's Development Planning and Coordinating Agency (NEPAD Agency) with funding from Wellcome [107769] and the UK government. The Gambian work was supported by the UK MRC (U1232661351, U105960371 and MC-A760-5QX00) and DFID under the MRC/DFID Concordat. The views expressed in this publication are those of the authors and not necessarily those of AAS, NEPAD Agency, Wellcome or the UK government. For the purpose of Open Access, the authors have applied a CC-BY public copyright licence to any author accepted manuscript version arising from this submission. The funders had no role in the study design, data collection, data analysis, data interpretation, or writing of the report.

\section{Availability of data and materials}

The data and analyses scripts underlying this article are available in Harvard Dataverse at https://doi.org/10.7910/DVN/MH1LPE and applications for data access can be made through the Kilifi Data Governance Committee cgmrc@kemri-wellcome.org.

\section{Declarations}

\section{Ethics approval and consent to participate}

Informed written consent was obtained from all children's parents or guardians before inclusion in the study. Ethical approvals were granted by the Scientific Ethics Review Unit of the Kenya Medical Research Institute (KEMRI/SERU/CGMRC/046/3257) in Kenya, the Uganda Virus Research Institute (GC/127/12/07/32) and Uganda National Council for Science and Technology (MV625) in Uganda, by Ministere de la Recherche Scientifique et de I'Innovation (reference 2014-12151 ) in Burkina Faso, the Gambian Government and the Medical Research Council Ethics Review Committee in The Gambia (874/830), the University of Witwatersrand Human Research Ethics Committee (M130714) in South Africa and in the UK by the London School of Hygiene and Tropical Medicine (A340) and the Oxford Tropical Research Ethics Committees (39-12, 41-12, 42-14, and 1042-13).

\section{Consent for publication}

Not applicable.

\section{Competing interests}

The authors declare that they have no competing interests.

\section{Author details}

${ }^{1}$ Kenya Medical Research Institute (KEMRI) Centre for Geographic Medicine Coast, KEMRI-Wellcome Trust Research Programme, Kilifi, Kenya.

${ }^{2}$ KEMRI-Wellcome Trust Research Programme - Accredited Research Centre, Open University, Kilifi, Kenya. ${ }^{3}$ Department of Clinical Biochemistry, Oxford University Hospitals, Oxford, UK. 'Wellcome Centre for Human Genetics, Nuffield Department of Medicine, University of Oxford, Oxford, UK. ${ }^{5}$ Li Ka Shing Centre for Health Information and Discovery, Big Data Institute, University of Oxford, Oxford, UK. ${ }^{6}$ Medical Research Council (MRC) Tropical Epidemiology Group, Department of Infectious Disease Epidemiology, London School of Hygiene and Tropical Medicine, London, UK. ${ }^{7}$ African Leadership in Vaccinology Expertise (Alive), Faculty of Health Sciences, University of the Witwatersrand, Johannesburg, South Africa. ${ }^{8}$ Groupe de Recherche Action en Sante (GRAS), 06, 06 BP 10248, Ouagadougou, Burkina Faso. ${ }^{9}$ Medical Research Council/Uganda Virus Research Institute and London School of Hygiene and Tropical Medicine Uganda Research Unit, Entebbe, Uganda. ${ }^{10}$ South African Medical Research Council Vaccines and Infectious Diseases Analytical Research Unit, Faculty of Health Sciences, University of the Witwatersrand, Johannesburg, South Africa. ${ }^{11}$ Wellcome Sanger Institute, Hinxton, Cambridge, UK. ${ }^{12}$ MRC Unit The Gambia at London School of Hygiene and Tropical Medicine, Banjul, The Gambia. ${ }^{13}$ Centre for Tropical Medicine and Global Health, Nuffield Department of Medicine, University of Oxford, Oxford, UK. ${ }^{14}$ South African Medical Research Council/Wits Developmental Pathways for Health Research Unit, Department of Paediatrics, University of the Witwatersrand, Johannesburg, South Africa. ${ }^{15}$ Department of Clinical Research, London School of Hygiene and Tropical Medicine, London, UK. ${ }^{16} \mathrm{Centre}$ for Research on Genomics and Global Health, National Human Genome Research Institute, National Institutes of Health, South Drive, MSC 5635, Bethesda, Maryland 20891-5635, USA.

${ }^{17}$ Department of Infectious Diseases and Institute of Global Health Innovation, Imperial College, London, UK. ${ }^{18}$ Department of Paediatrics, University of Oxford, Oxford, UK. 
Received: 15 December 2020 Accepted: 16 April 2021 Published online: 20 May 2021

\section{References}

1. Holick MF. Vitamin D deficiency. N Engl J Med. 2007;357(3):266-81. https:// doi.org/10.1056/NEJMra070553.

2. Mogire RM, Mutua A, Kimita W, Kamau A, Bejon P, Pettifor JM, et al. Prevalence of vitamin D deficiency in Africa: a systematic review and metaanalysis. Lancet Glob Health. 2020;8(1):e134-42. https://doi.org/10.1016/ S2214-109X(19)30457-7.

3. Weydert JA. Vitamin D in Children's Health. Children (Basel). 2014;1(2):20826. https://doi.org/10.3390/children1020208.

4. Jones KDJ, Hachmeister CU, Khasira M, Cox L, Schoenmakers I, Munyi C, et al. Vitamin D deficiency causes rickets in an urban informal settlement in Kenya and is associated with malnutrition. Matern Child Nutr. 2018;14(1): e12452. https://doi.org/10.1111/mcn.12452.

5. Kyu HH, Pinho C, Wagner JA, Brown JC, Bertozzi-Villa A, Charlson FJ, et al. Global and National Burden of Diseases and Injuries Among Children and Adolescents Between 1990 and 2013: Findings From the Global Burden of Disease 2013 Study. JAMA Pediatr. 2016;170(3):267-87. https://doi.org/10.1 001/jamapediatrics.2015.4276.

6. Amukele TK, Soko D, Katundu P, Kamanga M, Sun J, Kumwenda NI, et al. Vitamin D levels in Malawian infants from birth to 24 months. Arch Dis Child. 2013;98(3):180-3. https://doi.org/10.1136/archdischild-2012-302377.

7. Aydemir G, Cekmez F, Kalkan G, Fidanci MK, Kaya G, Karaoglu A, et al. High serum 25-hydroxyvitamin D levels are associated with pediatric sepsis. Tohoku J Exp Med. 2014;234(4):295-8. https://doi.org/10.1620/tjem.234.295.

8. Pfitzner MA, Thacher TD, Pettifor JM, Zoakah Al, Lawson JO, Isichei CO, et al. Absence of vitamin D deficiency in young Nigerian children. J Pediatr. 1998; 133(6):740-4. https://doi.org/10.1016/S0022-3476(98)70143-X.

9. Sudfeld CR, Manji KP, Smith ER, Aboud S, Kisenge R, Fawzi WW, et al. Vitamin D deficiency is not associated with growth or the incidence of common morbidities among Tanzanian infants. J Pediatr Gastroenterol Nutr. 2017;65(4):467-74. https://doi.org/10.1097/MPG.0000000000001658.

10. Sudfeld CR, Duggan C, Aboud S, Kupka R, Manji KP, Kisenge R, et al. Vitamin $\mathrm{D}$ status is associated with mortality, morbidity, and growth failure among a prospective cohort of HIV-infected and HIV-exposed Tanzanian infants. J Nutr. 2015;145(1):121-7. https://doi.org/10.3945/jn.114.201566.

11. Djennane M, Lebbah S, Roux C, Djoudi H, Cavalier E, Souberbielle JC. Vitamin D status of schoolchildren in Northern Algeria, seasonal variations and determinants of vitamin D deficiency. Osteoporos Int. 2014;25(5):1493502. https://doi.org/10.1007/s00198-014-2623-7.

12. Poopedi MA, Norris SA, Pettifor JM. Factors influencing the vitamin D status of 10-year-old urban South African children. Public Health Nutr. 2011;14(2): 334-9. https://doi.org/10.1017/\$136898001000234X.

13. Williams DM, Fraser A, Sayers A, Fraser WD, Hingorani A, Deanfield J, et al. Associations of 25-hydroxyvitamin D2 and D3 with cardiovascular risk factors in childhood: cross-sectional findings from the Avon Longitudinal Study of Parents and Children. J Clin Endocrinol Metab. 2012;97(5):1563-71. https://doi.org/10.1210/jc.2011-2335.

14. Mazidi M, Rezaie P, Vatanparast H. Impact of vitamin D supplementation on C-reactive protein; a systematic review and meta-analysis of randomized controlled trials. BMC Nutrition. 2018;4(1):1. https://doi.org/10.1186/s40795017-0207-6.

15. Cusick SE, Opoka RO, Lund TC, John CC, Polgreen LE. Vitamin D insufficiency is common in Ugandan children and is associated with severe malaria. Plos One. 2014;9(12):e113185. https://doi.org/10.1371/journal.pone. 0113185.

16. Bikle DD, Schwartz J. Vitamin D binding protein, total and free vitamin D levels in different physiological and pathophysiological Conditions. Front Endocrinol (Lausanne). 2019;10:317. https://doi.org/10.3389/fendo.2019.00317.

17. Powe CE, Evans MK, Wenger J, Zonderman AB, Berg AH, Nalls $M$, et al. Vitamin D-binding protein and vitamin D status of black Americans and white Americans. N Engl J Med. 2013;369(21):1991-2000. https://doi.org/10.1 056/NEJMoa1306357.

18. Arnaud J, Constans J. Affinity differences for vitamin D metabolites associated with the genetic isoforms of the human serum carrier protein (DBP). Hum Genet. 1993;92(2):183-8. https://doi.org/10.1007/BF00219689.

19. Braithwaite VS, Jones KS, Schoenmakers I, Silver M, Prentice A, Hennig BJ. Vitamin D binding protein genotype is associated with plasma $25 \mathrm{OHD}$ concentration in West African children. Bone. 2015;74:166-70. https://doi. org/10.1016/j.bone.2014.12.068.

20. Jones KS, Assar S, Harnpanich D, Bouillon R, Lambrechts D, Prentice A, et al. $25(\mathrm{OH}) \mathrm{D} 2$ half-life is shorter than $25(\mathrm{OH}) \mathrm{D} 3$ half-life and is influenced by DBP concentration and genotype. J Clin Endocrinol Metab. 2014;99(9):337381. https://doi.org/10.1210/jc.2014-1714.

21. Bejon P, Williams TN, Liljander A, Noor AM, Wambua J, Ogada E, et al. Stable and unstable malaria hotspots in longitudinal cohort studies in Kenya. Plos Med. 2010;7(7):e1000304. https://doi.org/10.1371/journal.pmed.1000304.

22. Elliott AM, Kizza M, Quigley MA, Ndibazza J, Nampijja M, Muhangi L, et al. The impact of helminths on the response to immunization and on the incidence of infection and disease in childhood in Uganda: design of a randomized, double-blind, placebo-controlled, factorial trial of deworming interventions delivered in pregnancy and early childhood [ISRC TN32849447]. Clin Trials. 2007:4(1):42-57. https://doi.org/10.1177/1740774 506075248 .

23. Tiono AB, Nebie I, Anagnostou N, Coulibaly AS, Bowyer G, Lam E, et al. First field efficacy trial of the ChAd63 MVA ME-TRAP vectored malaria vaccine candidate in 5-17 months old infants and children. Plos One. 2018;13(12): e0208328. https://doi.org/10.1371/journal.pone.0208328.

24. Nunes $M C$, Cutland $C L$, Jones $S$, Hugo A, Madimabe R, Simões EAF, et al. Duration of infant protection against influenza illness conferred by maternal immunization. JAMA Pediatr. 2016;170(9):840-7. https://doi.org/10.1001/jama pediatrics.2016.0921.

25. Atkinson SH, Rockett K, Sirugo G, Bejon PA, Fulford A, O'Connell MA, et al. Seasonal childhood anaemia in West Africa is associated with the haptoglobin 2-2 genotype. Plos Med. 2006;3(5):e172. https://doi.org/10.13 71/journal.pmed.0030172.

26. Hutchinson $K$, Healy M, Crowley V, Louw M, Rochev Y. Verification of Abbott 25-OH-vitamin D assay on the architect system. Pract Lab Med. 2017;7:2735. https://doi.org/10.1016/j.plabm.2017.01.001.

27. Holick MF, Binkley NC, Bischoff-Ferrari HA, Gordon CM, Hanley DA, Heaney $\mathrm{RP}$, et al. Evaluation, treatment, and prevention of vitamin D deficiency: an Endocrine Society clinical practice guideline. J Clin Endocrinol Metab. 2011; 96(7):1911-30. https://doi.org/10.1210/jc.2011-0385.

28. Ross AC, Manson JE, Abrams SA, Aloia JF, Brannon PM, Clinton SK, et al. The 2011 report on dietary reference intakes for calcium and vitamin D from the Institute of Medicine: what clinicians need to know. J Clin Endocrinol Metab. 2011;96(1):53-8. https://doi.org/10.1210/jc.2010-2704.

29. Bouillon R, Carmeliet G. Vitamin D insufficiency: Definition, diagnosis and management. Best Pract Res Clin Endocrinol Metab. 2018;32(5):669-84. https://doi.org/10.1016/j.beem.2018.09.014.

30. World Health Organization, Centers for Disease Control. Assessing the iron status of populations: report of a Joint World Health Organization/Centers for Disease Control and Prevention Technical Consultation on the Assessment of Iron Status at the Population Level, Geneva, Switzerland, 6-8 April 2004. In: Assessing the iron status of populations: report of a Joint World Health Organization/Centers for Disease Control and Prevention Technical Consultation on the Assessment of Iron Status at the Population Level, Geneva, Switzerland, 6-8 April 2004; 2005.

31. World Health Organisation. WHO Child Growth Standards based on length/ height, weight and age. Acta Paediatr Suppl. 2006;450:76.

32. Eltahir EAB, Gong C. Dynamics of wet and dry years in West Africa. J Climate. 1996;9(5):1030-42. https://doi.org/10.1175/1520-0442(1996)009<103 0:DOWADY>2.0.CO;2.

33. Philippon N, Camberlin P, Moron V, Boyard-Micheau J. Anomalously wet and dry rainy seasons in Equatorial East Africa and associated differences in intra-seasonal characteristics. Climate Dynamics. 2015;45(7-8):2101-21. https://doi.org/10.1007/s00382-014-2460-6.

34. TO C, Herreros F, Zhang JH, Ellis BK, Simpson C, Torrealba-Fox E, et al. Demographic, dietary, and biochemical determinants of vitamin D status in inner-city children. Am J Clin Nutr. 2012;95(1):137-46. https://doi.org/10.394 5/ajcn.111.018721.

35. Nakano S, Suzuki M, Minowa K, Hirai S, Takubo N, Sakamoto Y, et al. Current Vitamin D Status in Healthy Japanese Infants and Young Children. J Nutr Sci Vitaminol (Tokyo). 2018;64(2):99-105. https://doi.org/10.3177/jnsv.64.99.

36. Guo Y, Ke HJ, Liu Y, Fu M, Ning J, Yu L, et al. Prevalence of vitamin D insufficiency among children in southern China: A cross-sectional survey. Medicine (Baltimore). 2018;97(25):e11030. https://doi.org/10.1097/MD. 0000000000011030 . 
37. Prentice A, Schoenmakers I, Jones KS, Jarjou LM, Goldberg GR. Vitamin D deficiency and its health consequences in Africa. Clin Rev Bone Miner Metab. 2009;7(1):94-106. https://doi.org/10.1007/s12018-009-9038-6.

38. Poopedi MA, Norris SA, Micklesfield LK, Pettifor JM. Does vitamin D status track through adolescence? Am J Clin Nutr. 2015;102(5):1025-9. https://doi. org/10.3945/ajcn.115.112714

39. Wakayo T, Belachew T, Vatanparast H, Whiting SJ. Vitamin D deficiency and its predictors in a country with thirteen months of sunshine: the case of school children in central Ethiopia. Plos One. 2015;10(3):e0120963. https:// doi.org/10.1371/journal.pone.0120963.

40. Kunz C, Hower J, Knoll A, Ritzenthaler KL, Lamberti T. No improvement in vitamin D status in German infants and adolescents between 2009 and 2014 despite public recommendations to increase vitamin D intake in 2012. Eur J Nutr. 2018;58(4):1711-22. https://doi.org/10.1007/s00394-018-1717-y.

41. Mokhtar RR, Holick MF, Sempertegui F, Griffiths JK, Estrella B, Moore LL, et al. Vitamin D status is associated with underweight and stunting in children aged 6-36 months residing in the Ecuadorian Andes. Public Health Nutr. 2018;21(11):1974-85. https://doi.org/10.1017/S1368980017002816.

42. Avagyan D, Neupane SP, Gundersen TE, Madar AA. Vitamin D status in preschool children in rural Nepal. Public Health Nutr. 2016;19(3):470-6. https:// doi.org/10.1017/S136898001500083X.

43. Amer M, Qayyum R. Relation between serum 25-hydroxyvitamin D and Creactive protein in asymptomatic adults (from the Continuous National Health and Nutrition Examination Survey 2001 to 2006). Am J Cardiol. 2012; 109(2):226-30. https://doi.org/10.1016/j.amjcard.2011.08.032.

44. Toko EN, Sumba OP, Daud II, Ogolla S, Majiwa M, Krisher JT, et al. Maternal vitamin D status and adverse birth outcomes in children from rural Western Kenya. Nutrients. 2016;8(12):794. https://doi.org/10.3390/nu8120794.

45. Yakoob MY, Salam RA, Khan FR, Bhutta ZA. Vitamin D supplementation for preventing infections in children under five years of age. Cochrane Database Syst Rev. 2016;11:CD008824.

46. Newton DA, Baatz JE, Kindy MS, Gattoni-Celli S, Shary JR, Hollis BW, et al. Vitamin $D$ binding protein polymorphisms significantly impact vitamin $D$ status in children. Pediatr Res. 2019;86(5):662-9. https://doi.org/10.1038/s413 90-019-0322-y.

47. Carter GD, Phinney KW. Assessing vitamin D status: time for a rethink? Clin Chem. 2014;60(6):809-11. https://doi.org/10.1373/clinchem.2013.219386.

48. Yousefzadeh P, Shapses SA, Wang X. Vitamin D binding protein impact on 25-hydroxyvitamin D levels under different physiologic and pathologic conditions. Int J Endocrinol. 2014;2014:981581.

\section{Publisher's Note}

Springer Nature remains neutral with regard to jurisdictional claims in published maps and institutional affiliations.

Ready to submit your research? Choose BMC and benefit from:

- fast, convenient online submission

- thorough peer review by experienced researchers in your field

- rapid publication on acceptance

- support for research data, including large and complex data types

- gold Open Access which fosters wider collaboration and increased citations

- maximum visibility for your research: over $100 \mathrm{M}$ website views per year

At $\mathrm{BMC}$, research is always in progress.

Learn more biomedcentral.com/submissions 